\title{
SYNTHESIS, CHARACTERIZATION, AND BIOLOGICAL EVALUATION OF OXAZOLONE ANALOGS
}

\section{MUTHUBOOPATHI G, SHANMUGARAJAN TS*}

Department of Pharmaceutics, School of Pharmaceutical Sciences, VISTAS, Chennai - 600 117, Tamil Nadu, India. Email: mailshanmuga@gmail.com

Received: 10 October 2018, Revised and Accepted: 11 December 2018

ABSTRACT

Objective: The main objective of the study is to synthesize some novel oxazolone derivatives to evaluate for anti-inflammatory activity.

Methods: Acetylglycine was prepared using glycine and acetic anhydride, and the prepared acetylglycine was condensed with different aromatic aldehydes to get novel oxazolone derivatives. The synthesized compound was carried out the characterization by Fourier-transform infrared spectroscopy and find the anti-inflammatory by human red blood cell (HRBC) membrane stabilization method.

Results: The anti-inflammatory activity was performed using novel oxazolone derivatives $\left(\mathrm{Cpd}_{1}, \mathrm{Cpd}_{2}, \mathrm{Cpd}_{3}\right.$, and $\left.\mathrm{Cpd}_{4}\right)$ and nimesulide (as standard) on HRBC membrane stabilization method. The percentage protection was observed using colorimeter. The synthesized oxazolone was compared with the standard drug nimesulide for anti-inflammatory using HRBC membrane stabilizing method. All the synthesized oxazolone derivatives have shown the anti-inflammatory activity as that of standard. The results can be easily interpreted using histograms.

Conclusions: Among all the synthesized compounds, oxazolone with 4-chlorobenzaldehyde shows more anti-inflammatory activity when compared with the other oxazolone derivatives.

Keywords: Glycine, Acetic anhydride, Acetyl glycine, Oxazolone analogs, Fourier-transform infrared spectroscopy, Anti-inflammatory, Human red blood cell membrane stabilization method.

(C) 2018 The Authors. Published by Innovare Academic Sciences Pvt Ltd. This is an open access article under the CC BY license (http://creativecommons. org/licenses/by/4. 0/) DOI: http://dx.doi.org/10.22159/ajpcr.2018.v11s4.31726

\section{INTRODUCTION}

Oxazolones are being synthesized in many ways since 1883. These are five-membered heterocyclic compounds containing oxygen and nitrogen as hetero atoms which exist in three isomeric forms, according to the location of the carbonyl group and location of the double bonds. These have acquired more importance in recent years due to their pharmacological activities.

The C-2 and C-4 positions of oxazolone are responsible for their various biological activities such as analgesic, anti-inflammatory, antidepressant, anticancer, antimicrobial, antidiabetic, and antiobesity. Oxazol-5-ones contain numerous reactive sites allowing for a diverse set of possible modifications and are an important pharmacophore of synthesized drugs $[1,2]$

Oxazolones are important intermediate for the synthesis of several compounds such as amino alcohols, amides, amino acids, dyes, heterocyclic precursors, biological active compounds as well as biosensors coupling and photosensitive composition devices for proteins [3].

A novel class of oxazolone compounds will bind complementary DNA and RNA strands more strongly than the corresponding natural DNA or RNA strands and therby exhibit increased sequence specificity and solubility. This peptidomimetic synthesis can lead to enhanced properties of the required proteins, which are required to do characteristic functions [5-7]

The present study was performed to enhance the anti-inflammatory activity and to minimize the dose and side effects that were caused due to the over dose of marketed standard drugs.

\section{MATERIALS AND METHODS}

\section{Materials}

Chemicals

Silica gel (Research Lab Fine Chem Industry), methanol (JiangseHauxi International Trade Co Ltd.), and benzaldehyde, furfuraldehyde, 4-chlorobenzaldehyde and 4-fluorobenzaldehyde, aceticanhydride, anhydrous sodium acetate, glycine, and chloroform all chemicals were purchased from Research Lab Fine Chem Industry.

\section{Equipment}

Magnetic stirrer (Remi ZMCH), Hot air oven (Kemi), and vacuum pump were used.

\section{Apparatus}

Round bottomed flask, condenser, beaker, conical flask, thin-layer chromatography (TLC) plates, funnels, tripod stand, burner, water bath, capillary tube, and glass rod were required.

\section{Methods}

General method for the synthesis of oxazolone derivatives

Step 1: Preparation of acetyl glycine

Acetylglycine was prepared by taking equimolar quantity of glycine and water in a $500 \mathrm{ml}$ conical flask. Then, a mechanical stirrer was introduced and stirred vigorously until the solid is almost completely dissolved. Equimolar quantity of acetic anhydride was added in one portion and stirred vigorously for 15-20 min, when the solution became hot, some crystals of acetylglycine may be separated out. Then, it is cooled in a refrigerator, preferably overnight. Then, the precipitate is collected on a Buchner funnel and is washed with ice cold water and dried at $100^{\circ} \mathrm{C}$. 


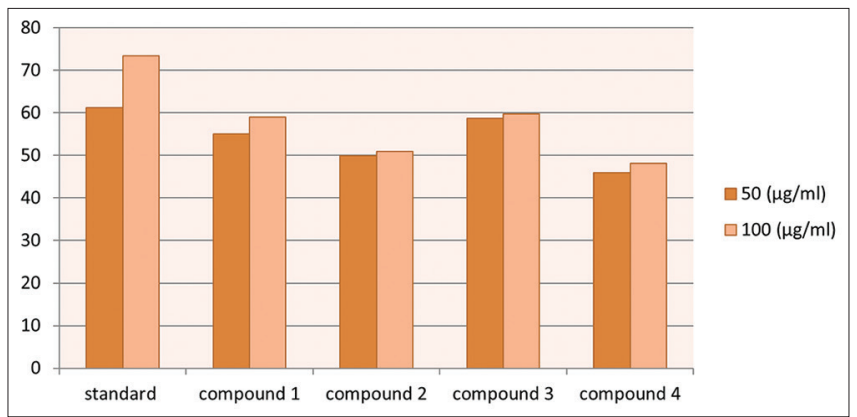

Fig. 1: Graphical representation of anti-inflammatory activity. Compound 1: Oxazolone+Benzaldehyde. Compound 2:

Oxazolone+4-Flurobenzaldehyde. Compound 3: Oxazolone+4Chlorobenzaldehyde. Compound 4: Oxazolone+Furfuraldehyde

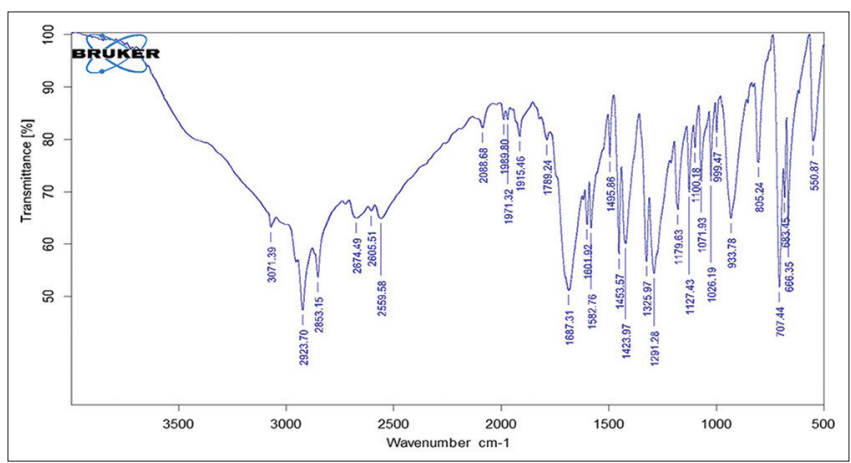

Fig. 2: Charecterization of oxazolone analogs (Compound I Oxazolone+Benzaldehyde)

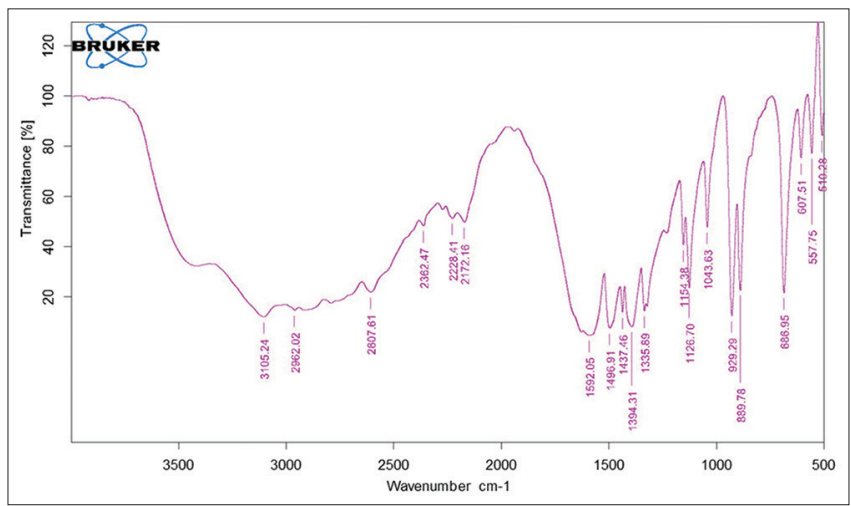

Fig. 3: Charecterization of oxazolone analogs (Compound II Oxazolone+4-Flurobenzaldehyde)

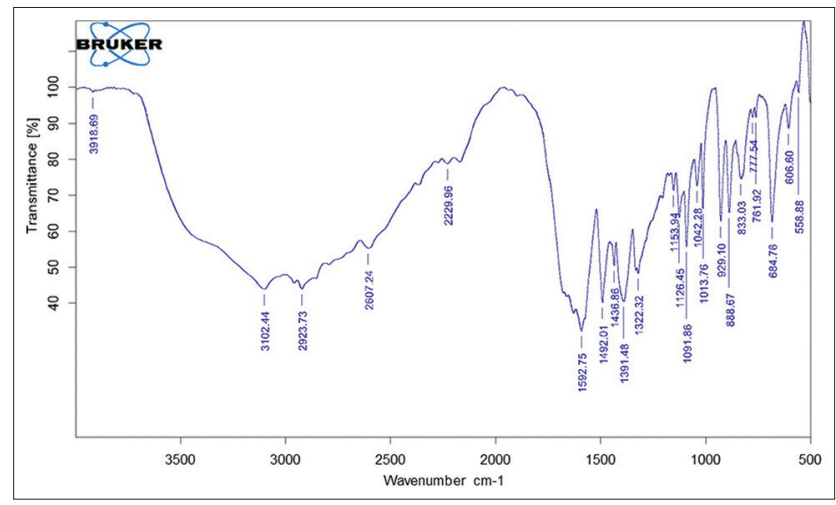

Fig. 4: Charecterization of oxazolone analogs (compound III Oxazolone+4- Chlorobenzaldehyde)
Step 2: Preparation of 4-(benzylidene)-2-methyl oxazole-5-one Equimolar quantity of acetyleglycine, substituted aromatic aldehyde, anhydrous sodium acetate, and acetic anhydride are taken in a $500 \mathrm{ml}$ round bottom flask (equipped with a reflex condenser) on a water bath with occasional stirring until solution is completed (10-20 min). The resulted solution is boiled for $1 \mathrm{~h}$, then it is cooled, and it is kept in refrigerator overnight. The solid masses of yellow crystals were separated out and washed with cold water. Then filtered through a Buchner funnel, and again washed well with cold water.

Reaction 1

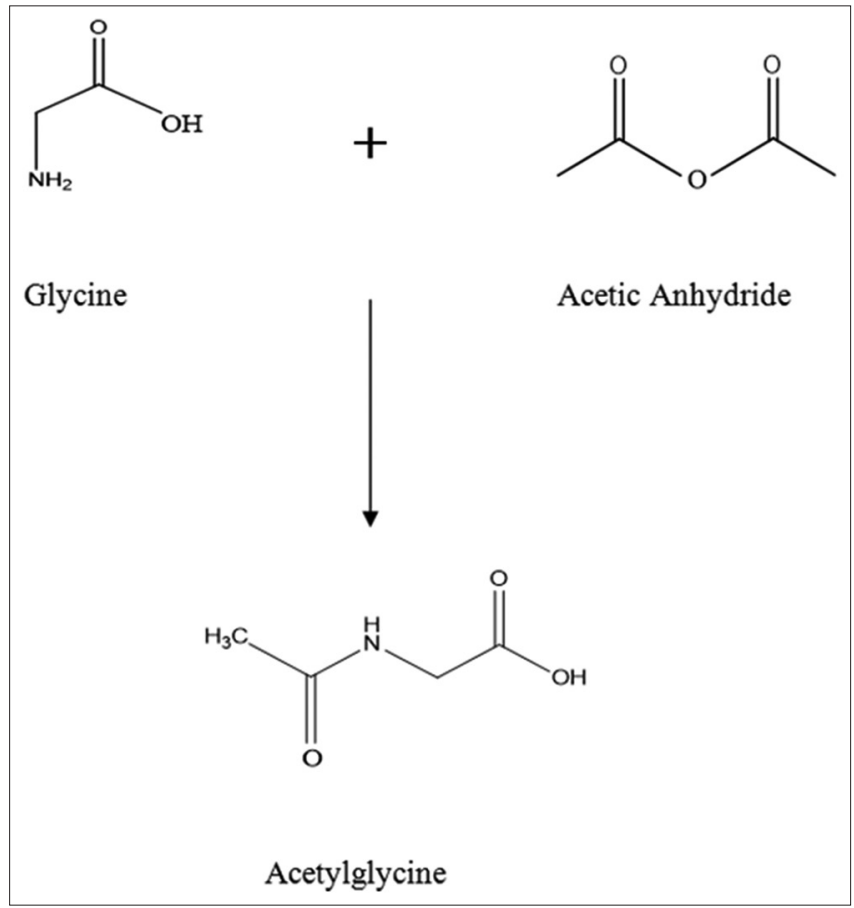

Reaction 2<smiles></smiles>

Acetylglycine

$\mathrm{CH}_{3} \mathrm{COONa}$

$\left(\mathrm{CH}_{3} \mathrm{COO}\right)_{2}$ 
Table 1: Anti-inflammatory activity

\begin{tabular}{|c|c|c|c|c|c|}
\hline \multirow[t]{2}{*}{ S. No. } & \multirow[t]{2}{*}{ Compound } & \multicolumn{2}{|l|}{ OD value } & \multicolumn{2}{|c|}{$\%$ protection } \\
\hline & & $50(\mu \mathrm{g} / \mathrm{ml})$ & $100(\mu \mathrm{g} / \mathrm{ml})$ & $50(\mu \mathrm{g} / \mathrm{ml})$ & $100(\mu \mathrm{g} / \mathrm{ml})$ \\
\hline 1. & Standard & $0.19 \pm 0.05$ & $0.13 \pm 0.05$ & 61.2 & 73.4 \\
\hline 2. & Compound 1 & $0.22 \pm 0.08$ & $0.20 \pm 0.02$ & 55.1 & 59.1 \\
\hline 3. & Compound 2 & $0.25 \pm 0.002$ & $0.24 \pm 0.001$ & 49.9 & 51.0 \\
\hline 4. & Compound 3 & $0.31 \pm 0.08$ & $0.26 \pm 0.011$ & 55.8 & 59.8 \\
\hline 5. & Compound 4 & $0.43 \pm 0.02$ & $0.40 \pm 0.01$ & 59.8 & 48.1 \\
\hline
\end{tabular}

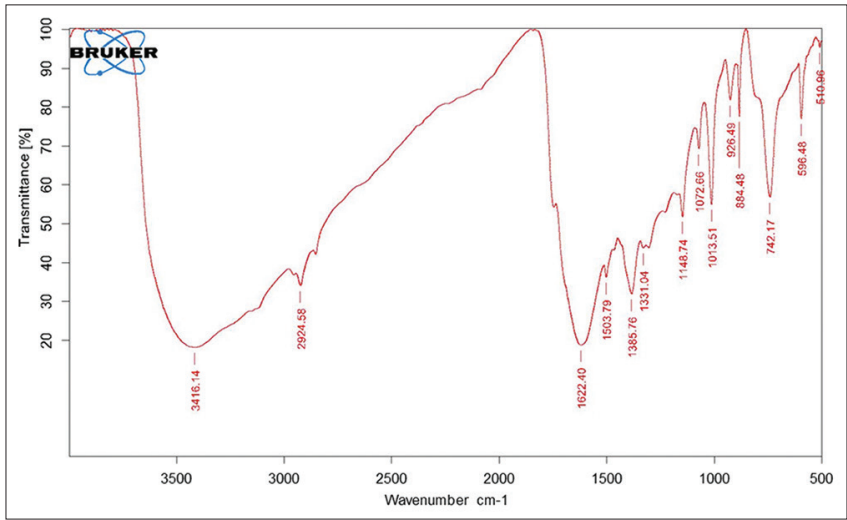

Fig. 5: Charecterization of oxazolone analogs (Compound IV Oxazolone+Furfuraldehyde)

\section{Screening for anti-inflammatory activity}

Human red blood cell (HRBC) membrane stabilization method[4] The human blood was collected from the volunteers. Then, the blood was mixed $(2 \%$ dextrose, $0.8 \%$ sodium citrate, $0.05 \%$ citric acid and $0.42 \%$ sodium chloride in water). Then, it was centrifuged at $3000 \mathrm{rpm}$. The centrifuged cells were washed with isosaline. The assay mixture contained the $1 \mathrm{ml}$ of phosphate buffer $(0.15 \mathrm{M}, \mathrm{pH} 7.4), 0.5 \mathrm{ml}$ of red blood cell suspension, and $2 \mathrm{ml}$ of hyposaline $(0.36 \%)$. Test drug concentration of $50 \mu \mathrm{g} / \mathrm{ml}$ and $100 \mu \mathrm{g} / \mathrm{ml}$ diclofenac sodium was used as the reference drug. Instead of hyposaline, $2 \mathrm{ml}$ of distilled water was used as control. Finally, the assay mixtures were centrifuged after incubation at normal room temperature. The supernatant solution was used for the estimation of hemoglobin using colorimeter at $560 \mathrm{~nm}$. The hemolysis was calculated by assuming the hemolysis produced in the presence of distilled water as $100 \%$.

\section{RESULTS}

During the synthesis of oxazolone analogs, the end point for each step was identified by performing TLC. The $\mathrm{R}_{f}$ value was measured for every 30 min until two consecutive $\mathrm{R}_{f}$ values were obtained.

\section{DISCUSSION}

The $\mathrm{R}_{f}$ values were used to determine the end point of each step involved in the synthesis of oxazolone derivatives. Two consecutive constant $\mathbf{R}_{f}$ values represent that the reaction is complete.

The anti-inflammatory activity (Fig. 1) was performed using novel oxazolone derivatives $\left(\mathrm{Cpd}_{1}, \mathrm{Cpd}_{2}, \mathrm{Cpd}_{3}\right.$, and $\left.\mathrm{Cpd}_{4}\right)$ (Figs. 2-5) and nimesulide (as standard) on HRBC membrane stabilization method Table 1. The percentage protection was observed using colorimeter.

The synthesized oxazolone was compared with the standard drug nimesulide for anti-inflammatory using HRBC membrane stabilizing method. All the synthesized oxazolone derivatives (benzaldehyde, 4-fluorobenzaldehyde, 4-chlorobenzaldehyde, and furfuraldehyde) have shown the anti-inflammatory activity as that of standard [8-13]. The results can be easily interpreted using histograms. The histogram was plotted which represents the effect of synthesized compounds with that of standard drug using blood sample.

Among all the synthesized compounds, oxazolone with 4-chlorobenzaldehyde shows more anti-inflammatory activity when compared with the other oxazolone derivatives [14-16].

\section{CONCLUSION}

The screening of literature has shown clearly that the synthesis and characterization of oxazolone derivatives using different aldehyde derivatives (benzaldehyde, 4-fluorobenzaldehyde, 4-chlorobenzaldehyde, and furfuraldehyde oxazolone derivatives) revealed that no anti- inflammatory work has been done so far.

The functional groups that were present in the synthesized compounds were identified using Fourier-transform infrared spectroscopy. The novel synthesis of oxazolone derivatives showed significant difference from standard drugs in percentage protection, especially it was found more in the oxazolone derivative of 4-chlorobenzaldehyde.

The anti-inflammatory effect of synthesized compounds was significant when compared with the standard drug nimesulide.

\section{REFERENCES}

1. Ahluwalia KV. Erlenmeyer-plochl azalactone and amino acid synthesis. In: Comprehensive Practical Organic Chemistry. Preparations and Quantitative Analysis. Newdelhi: Universities Press; 2000.

2. Anosike CA, Obidoa O, Ezeanyika LU. Membrane stabilization as a mechanism of the anti-inflammatory activity of methanol extract of garden egg (Solanum aethiopicum). Daru 2012;20:76.

3. Stinchcomb AL. In vivo evaluation of a transdermal codrug of 6- $\beta$-naltrexol linked to hydroxybupropion in hairless guinea pigs. Eur J Pharm Sci 2008;33:371-9.

4. Boniface PK, Verma S, Shukla A. Membrane stabilisation: A possible antiinflammatory mechanism for the extracts and compounds from Spathodea campanulata. Nat Prod Res 2014;28:2203-7.

5. Cushman DW, Cheung HS, Sbo EF, Ondetti MA. Design of potent competitive inhibitors of angiotensin converting enzyme. carboxyalkanoyl and mercaptoalkanoyl amino acids. Biochemistry 1977;16:5484-91.

6. Graves BJ, Hatada MH, Miller JK, Graves MC, Roy S, Cook CM, et al. The three dimensional x-ray crystal structure of HIV-1 protease complexed with a hydroxyethylene inhibitor. Adv Exp Med Biol 1991;306:455-60.

7. Griffin C, Karnik A, McNulty J, Pandey S. Pancratistatin selectively targets cancer cell mitochondria and reduces growth of human colon tumor xenografts. Mol Cancer Ther 2011;10:57.

8. Kim KH, Greco G, Novellino E. In: Kubinyi H, Folkers G, Martin YC, editors. 3D QSAR in Drug Design. Dordrecht: Kluwer Academic Publishers; 1998. p. 257.

9. Kuntz ID, Blaney JM, Oatley SJ, Langridge R, Ferrin TE. A geometric approach to macromolecule-ligand interactions. J Mol Biol 1982;161:269-88.

10. Osman MO, Hassan HM, Moawad EB, El-Mekabaty A. Reactivity of oxazolone derivative towards nitrogen and carbon nucleophilic reagents: Applications to the synthesis of new heterocycles. Int J Modern Org Chem 2013;2;11-25.

11. Sanchez C, Mendez C, Salas JA. Indolocarbazole natural products: Occurrence, biosynthesis and biological activity. Nat Prod Rep 
2006;23:1007-45

12. Seelmeier S, Schmidt H, Turk V, von der Helm K. Human immunodeficiency virus has an aspartic-type protease that can be inhibited by pepstatin A. Proc Natl Acad Sci USA 1988;85:6612-6.

13. Laeeq S, Sirbaiya AK, Siddiqui HH, Mehdi S, Zaidi H. An overview of the computer aided drug designing. World J Pharm Pharm Sci 2014;3:5.

14. Tandel RC, Mammen D. Synthesis and study of some compounds containingoxazoloneringshowingbiologicalactivity.IndianJChem 2008;
47:932-7.

15. Tikdari MA, Fozooni S, Hamidian H. Dodecatungstophosphoric acid (H3PW12O40), samarium and ruthenium (III) chloride catalyzed synthesis of unsaturated 2-phenyl-5(4H)-oxazolone derivatives under solvent-free conditions. Molecules 2008;13:3246-52.

16. Uwe R. The dynamic structure of jadomycin $b$ and the amino acid incorporation step of its biosynthesis. J Am Chem Soc 2004;126:4496-7. 